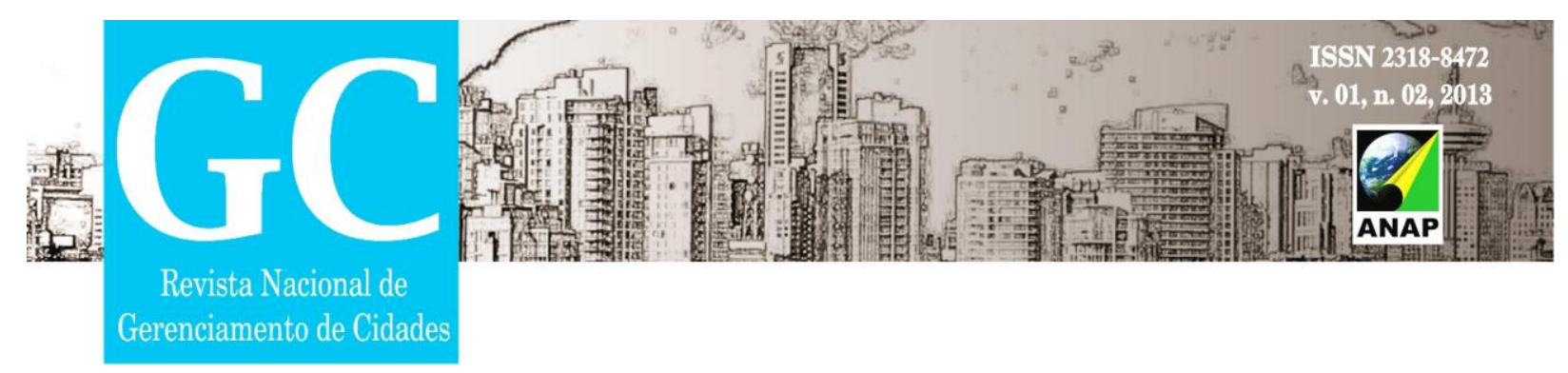

\title{
A DEGRADAÇÃO AMBIENTAL E A SUSTENTABILIDADE
}

\author{
Aiany Ruth Silva de Assis
}

\section{Manoel Rodrigues Chaves}

RESUMO: A sustentabilidade, que não deveria ser um problema, pode ser considerada como uma das questões relacionadas com o ambiente, porque é uma prática que não tem uma interpretação definida e sua efetiva implementação, como uma das mais viáveis soluções para a degradação ambiental, esbarra em vários obstáculos político-econômicos e sociais. Portanto, o estudo discute a real efetivação do desenvolvimento sustentável sem promover a degradação ambiental, indicando procedimentos que visualizem essa efetivação mais abrangente do que as ações e/ou atitudes relacionadas na maioria das literaturas sobre a sustentabilidade, podendo citar entre esses procedimentos a educação para o desenvolvimento sustentável que deverá promover valores que induzam o estabelecimento de relações de justiça, paz e negociação de interesses mútuos gerando mais igualdade, respeito e compreensão e com isso, mais respeito ao meio ambiente. Um dos problemas de proteção e conservação da natureza estão, na realidade, intimamente ligados aos problemas de sobrevivência do ser humano. Este estudo busca estabelecer um paralelo entre a prática da sustentabilidade e a degradação ambiental, fazendo entender que quando se fala em ambiente, a tendência é pensar nos inúmeros problemas do mundo atual, com relação à questão ambiental. A sustentabilidade confronta-se com um paradigma da sociedade em risco. Isso implica na necessidade de uma conscientização social em relação aos problemas ambientais, baseadas no acesso à informação e à Educação Ambiental (EA).

Palavras-chave: Sustentabilidade. Degradação ambiental. Educação Ambiental. 


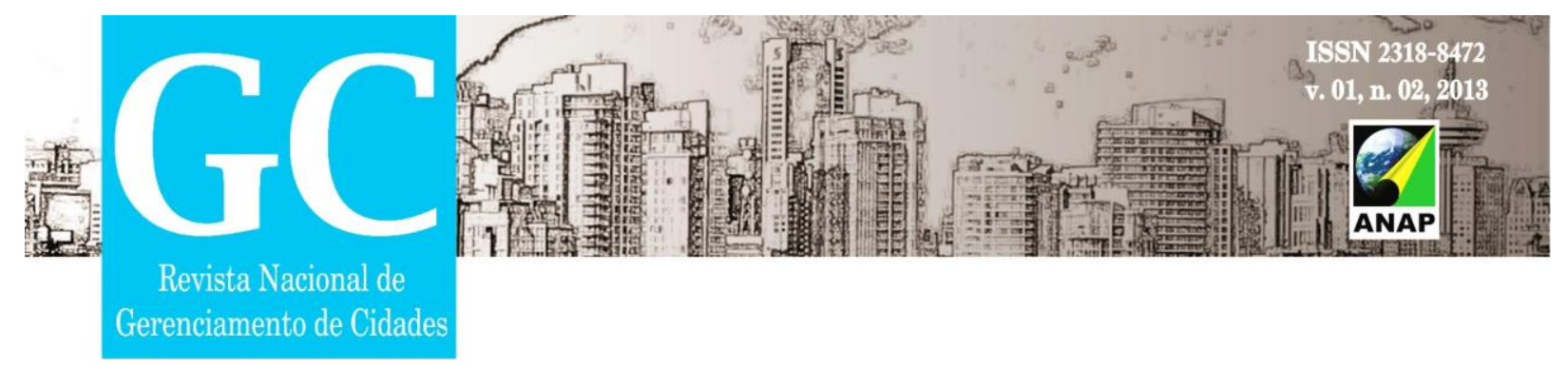

\section{INTRODUÇÃO}

A degradação socioambiental de que somos testemunhas é algo perverso, assim, os educadores ambientais necessitam partir para a prática educativa, superando as dificuldades e atingindo os objetivos de conscientização ambiental. Muitas vezes é dada à educação formal a incumbência de agenciar mudanças de comportamentos desejáveis na sociedade, e a ela se agregaram várias educações (sexual, antidroga, para o trânsito, para a saúde e higiene, para a cidadania, dentre outras). Nenhuma tem um apelo tão premente e globalizador quanto a Educação Ambiental (talvez pela sua própria natureza integradora que permeia várias áreas de conhecimento) e um impacto tão sério por conta das falhas no seu grande objetivo e/ou função que é o desenvolvimento da consciência crítica pela sociedade em relação à problemática ambiental e a todos os aspectos que a compõe.

O avanço acelerado da sociedade urbano-industrial tem provocado grandes impactos ao ambiente, especialmente a poluição do ar, das águas e do solo, o desmatamento, a desertificação, a extinção das espécies, o efeito estufa, a destruição da camada de ozônio e a formação da chuva ácida, e inúmeros outros. Em última instância, os estudiosos acreditam num colapso total dos sistemas naturais, uma vez que o modelo capitalista de crescimento ilimitado é incompatível com a finitude dos recursos do planeta.

Os ecossistemas não conseguem eliminar a enorme quantidade de detritos produzidos pela população e pelas indústrias e, segundo os ecologistas, a superação do problema do esgotamento da natureza envolve uma redefinição da ideia de progresso que precisa tornar-se ecologicamente sustentável.

Somente com a coesão da educação para o desenvolvimento sustentável, ampliada e abrangente com uma gestão ambiental comprometida com a compatibilidade entre o desenvolvimento sustentável e a finitude dos recursos naturais é que pode pensar em novas estratégias para a conservação da natureza, bem como, na possibilidade real de 


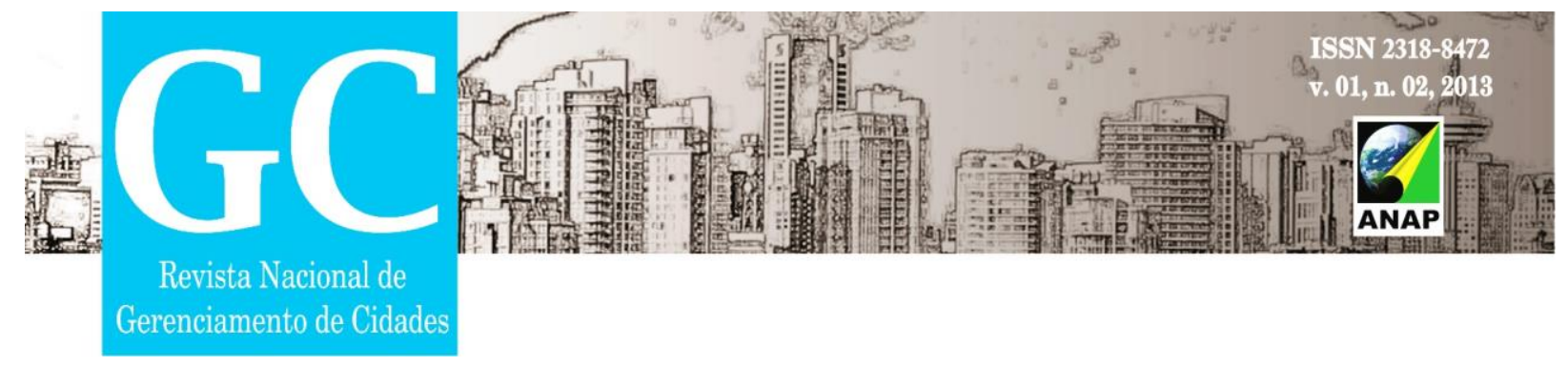

se fazer efetivas estratégias ai dispostas em forma de leis, reformas, decretos e práticas de sustentabilidade.

A Educação Ambiental está relacionada com a prática das tomadas de decisões e a ética que conduzem para a melhoria da qualidade de vida, buscando desenvolver mediante uma prática que vincula o educando com a comunidade, valores e atitudes que promovem um comportamento dirigido a transformação superadora da realidade, tanto em seus aspectos naturais como sociais, desenvolvendo no educando as habilidades e atitudes e competências voltadas para a construção de um ambiente saudável.

Desse modo, a questão que se apresenta neste ensaio teórico é condicionar um conhecimento real das implicações das práticas de sustentabilidade ambiental, enfocando a degradação ambiental, enquanto um processo pela qual se tem uma redução dos potenciais e recursos renováveis, provocada por uma combinação de agentes agindo sobre o ambiente em questão. Para que aconteçam essas ações conservacionistas, é necessário a reflexão e conhecimento das origens dos problemas ambientais, daí a importância da Educação Ambiental na formação de pessoas com atitudes que sejam coerentes com os princípios ambientais, bem como as formas de ser neste mundo pósmoderno.

\section{OBJETIVOS}

\subsection{Objetivo geral}

Estabelecer relações entre as práticas de sustentabilidade e degradação ambiental, considerando que são processos intervenientes e complementares, sendo que através da Educação Ambiental os problemas socioambientais podem ser minimizados.

\subsection{Objetivos específicos}




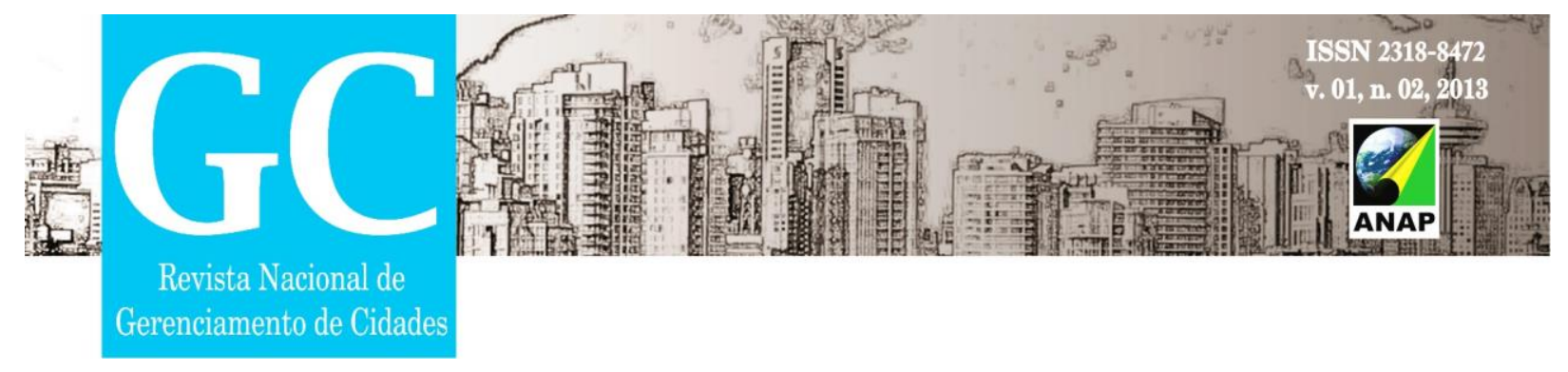

a) Conceituar sustentabilidade e degradação ambiental;

b) Discutir sobre a falta de compromisso da humanidade, de uma forma geral, com as questões ambientais;

c) Apontar procedimentos minimizadores de obstáculos político-econômicos e sociais frente à sustentabilidade.

d) Relatar a complexidade dos problemas ambientais que podem ser minimizadas através das práticas da Educação Ambiental.

\section{METODOLOGIA}

De acordo com Luna (1999, p. 8), "a pesquisa visa à produção de conhecimento novo para o preenchimento de lacunas numa dada área do conhecimento sobre as quais não há informações ou estas são insuficientes". Sendo assim, para se chegar a novas respostas faz-se o uso de metodologias, que devem possibilitar e facilitar o alcance dos objetivos propostos.

Este ensaio teórico possui cunho cientifico acadêmico e tem por método a pesquisa exploratória e descritiva. A metodologia utilizada na execução deste trabalho é de cunho qualitativo com revisões bibliográficas, buscando na literatura informações disponíveis e relevantes sobre a temática abordada, o estudo realizado baseia-se na observação dos fatos tal como ocorre na realidade.

A proposta de uma pesquisa qualitativa, que se aplica na busca de novos caminhos alternativos para verificar nas literaturas existentes informações disponíveis e relevantes sobre a evolução da degradação ambiental e a relação desta com o desenvolvimento sustentável. Em seguida buscou-se conceituar os termos sustentabilidade e degradação ambiental, apontando algumas das principais legislações que buscam efetivar a compreensão e ações acerca da relação sustentabilidade/degradação ambiental. Após a apresentação desta relação foi realizado um estudo sobre alternativas favoráveis o desmembramento dessa relação. 


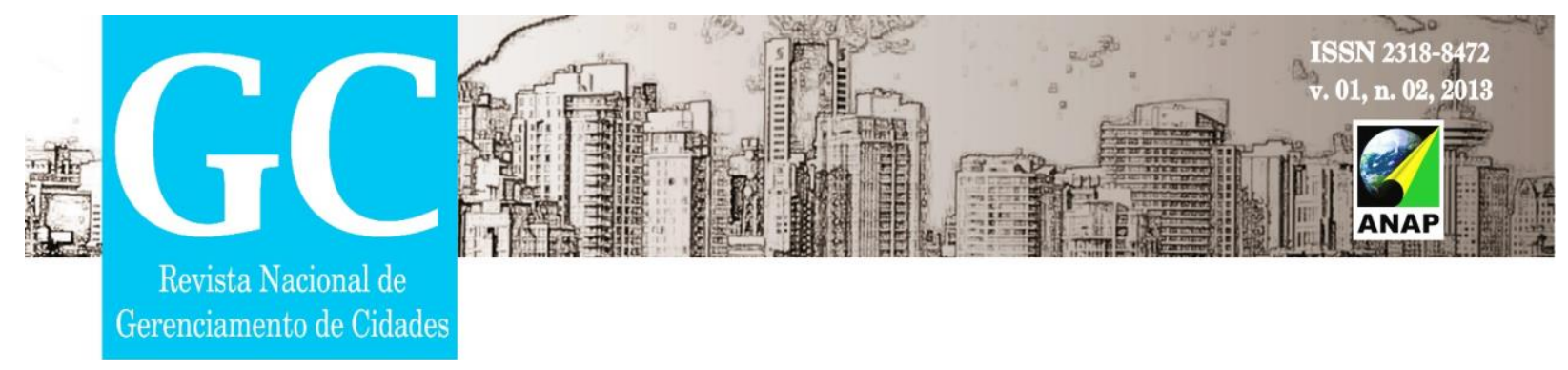

Dessa forma, e observando a necessidade de existir uma mudança de comportamento frente aos problemas ambientais e o uso racional dos recursos naturais, procurando um desenvolvimento econômico sem degradar o ambiente, a saber, que ações inconsequentes comprometem a vida das futuras gerações, e a necessidade de reconstruir relações sociais com o ambiente através da Educação Ambiental, que desenvolve nas pessoas uma consciência dos problemas ambientais é que surgiu o interesse de uma verificação objetiva e sucinta acerca dessa temática, considerando-se que a relação sustentabilidade e degradação são questões abrangentes e que merece reflexão e discussão.

\section{DISCUSSÃO}

Estudos demonstram que a preocupação e luta pela preservação do ambiente intensificou-se a partir da década de 1940 com a criação de uma série de organizações governamentais e não governamentais de atuação. Mas, "a internacionalização do debate em torno das questões ambientais concretiza-se, de fato, em 1972 com a realização, em Estocolmo, da Conferência das Nações Unidas sobre o ambiente humano". (ALMANAQUE ABRIL, 2007, p. 53)

De acordo com a mesma literatura, esse evento reuniu representantes de 113 países, de 250 organizações não governamentais e dos organismos da Organização das Nações Unidas (ONU) e teve como objetivo principal preparar os seguintes documentos: Declaração sobre o Meio Ambiente e Plano de Ação para o Ambiente. Dessa forma surgiu com mais veemência o termo desenvolvimento sustentável, quando várias entidades passaram a diagnosticar a situação ambiental e elaboraram estratégias globais para a preservação da natureza. Uma dessas estratégias é, justamente, o desenvolvimento sustentável, definido como:

[...] aquele que atende às necessidades do presente sem comprometer a possibilidade de as gerações futuras atenderem às suas próprias necessidades. $\mathrm{Na}$ prática, pressupõe a utilização de sistemas mais racionais de exploração da 


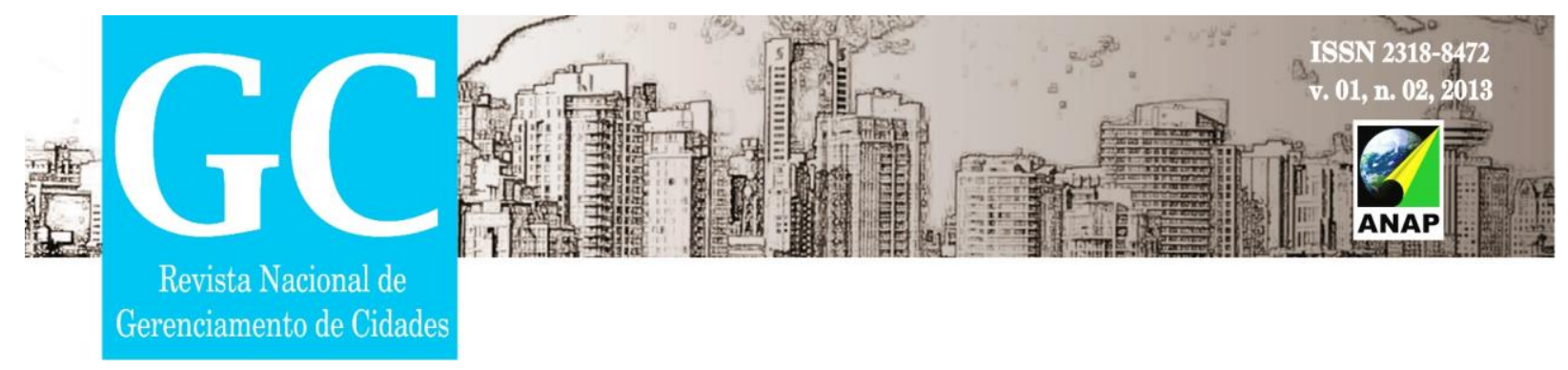

natureza, como as tecnologias não predatórias, preservar o equilíbrio ecológico. (ALMANAQUE ABRIL, 2007, p. 54)

Entende-se, portanto, que a sustentabilidade seja um termo usado para definir ações e atividades humanas que visam suprir as necessidades atuais dos seres humanos, sem comprometer o futuro das próximas gerações, estando diretamente relacionada ao desenvolvimento econômico e material sem agredir o ambiente, usando os recursos naturais de forma inteligente para que eles se mantenham no futuro.

Segundo Ruscheinsky (2003, p. 41),

[...] o futuro do ambiente requer o desenvolver da reflexão quanto um envolvimento com as alternativas, por isso para dar conta do enredo da sustentabilidade duas dimensões estão postas como desafio e perspectivas: a educação para o desenvolvimento sustentável e a gestão ambiental adequada.

Há divergências sobre o que vem a ser ambiente e, principalmente, sobre a relação consciente com a natureza. Desde 1960 estão se levantando grandes movimentos acerca da sua preservação, conservação e recuperação e entre esses movimentos está a Educação Ambiental, uma educação que busca a consciência crítica que permeia o entendimento e a intervenção de todos os setores da sociedade, encorajando o surgimento de um novo modelo de sociedade, em que a preservação dos recursos naturais seja compatível com o bem-estar socioeconômico da população. $\mathrm{O}$ ambiente pode ser definido de acordo com Reigota como sendo:

O lugar determinado ou percebido, onde os elementos naturais e sociais estão em relações dinâmicas. Essas relações implicam processos de criação cultural e tecnológica e processos históricos e sociais de transformação do meio natural e construído. (REIGOTA, 1998, p. 14)

É fundamental que cada pessoa desenvolva as suas potencialidades e adote posturas pessoais e comportamentos sociais construtivos, colaborando para a construção de uma sociedade socialmente justa, em um ambiente saudável e isso só será possível a partir de uma pedagogia inovadora, coletiva e prática. A EA é um processo individual e coletivo, vista como dimensão ambiental, não basta novas formas metodológicas e novos 


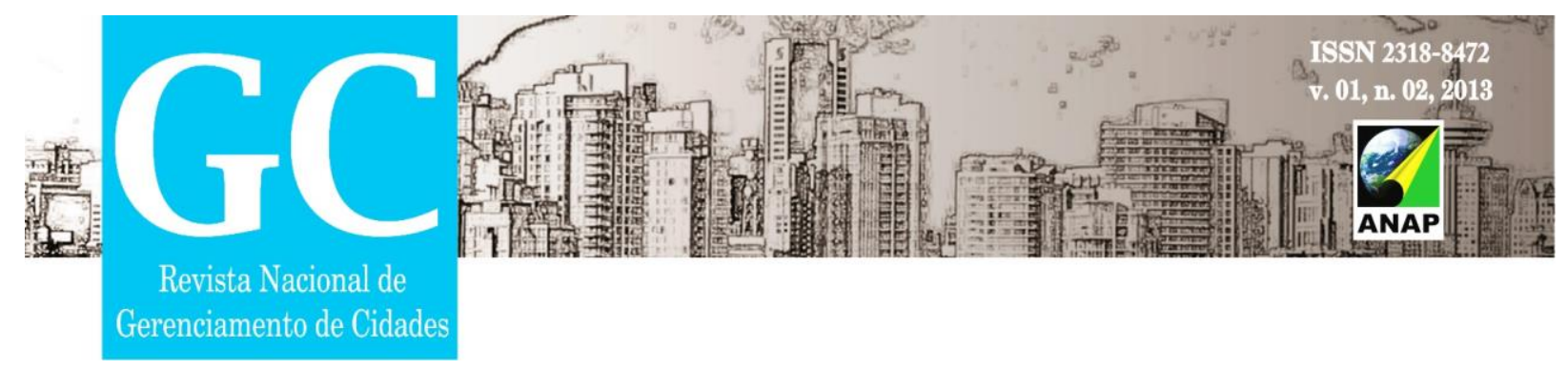

programas, a incorporação de conscientização ecológica e ambiental transmitida e compreendida pelos alunos, essa consciência ambiental é necessária para viver melhor, uma questão de sobrevivência das futuras gerações.

A EA busca desenvolver nas pessoas a capacidade crítica, o espírito de iniciativa e o senso de responsabilidade, para que ocorra a formação de uma cidadania com a visão objetiva do funcionamento da sociedade, motivada para vida coletiva e consciente de que a qualidade de vida das gerações futuras depende da forma com que o meio ambiente é tratado pelas gerações atuais.

\begin{abstract}
A reflexão sobre as práticas sociais, em um contexto marcado pela degradação permanente do meio ambiente e do seu ecossistema, envolve uma necessária articulação com a produção de sentidos sobre a Educação Ambiental. A dimensão ambiental configura-se crescentemente como uma questão que envolve um conjunto de atores do universo educativo, potencializando o engajamento dos diversos sistemas de conhecimento, a capacitação de profissionais e a comunidade universitária numa perspectiva interdisciplinar [...] (JACOBI, 2003, p. 1)
\end{abstract}

Nesse sentido, a EA proporciona conhecimentos científicos e tecnológicos aos cidadãos e as qualidades morais necessárias que lhes permitam desempenhar um papel efetivo na preparação e no manejo de processos de desenvolvimento que sejam compatíveis com a preservação do potencial produtivo do ambiente.

A Educação Ambiental como disciplina, além de ser um processo educacional das questões ambientais, alcança também os problemas socioeconômicos, políticos, culturais e históricos pela interação de uma forma ou de outra destes campos com o ambiente. Sua aplicação tem a extensão de auxiliar na formação da cidadania, de maneira que extrapola o aprendizado tradicional, fomentando o crescimento do cidadão e da Nação, daí sua importância.

Para Loureiro (2007, p. 38), "na atualidade, a Educação Ambiental assume um papel de grande relevância na formação socioambiental de cidadãos conscientes e responsáveis". É através da EA que poderá desenvolver a construção de novos conhecimentos e ajudar na compreensão do mundo globalizado. A EA já ocupa no currículo escolar, uma cadeira que integra exemplos teóricos e práticos, permitindo a 


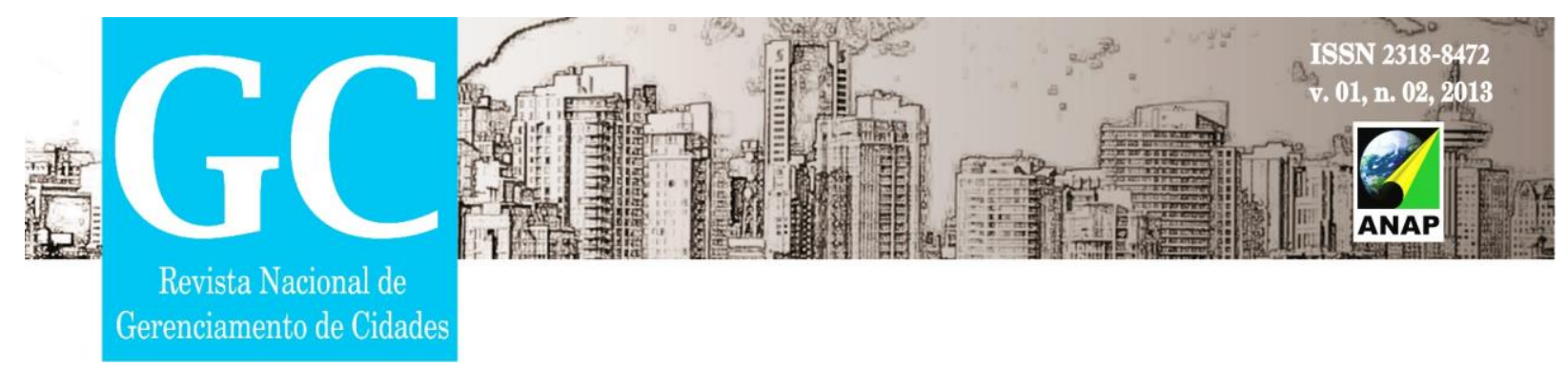

construção de um raciocínio crítico e reflexivo e possibilitando a visão de novas formas de desenvolver as atividades humanas visando à preservação do ambiente.

Vários estudos oferecem sugestões de ações e/ou atitudes relacionadas com o desenvolvimento sustentável e/ou sustentabilidade, por exemplo, exploração dos recursos vegetais de forma controlada, garantindo o replantio sempre que necessário; preservação integral as áreas verdes; incentivo à produção e consumo de alimentos orgânicos; exploração de recursos minerais de forma planejada e racionalizada; utilização de fontes de energia limpas e renováveis; reciclagem de resíduos sólidos; desenvolvimento da prática de gestão sustentável; adoção de medidas que visem a não poluição de recursos hídricos, dentre outras.

É pertinente sublinhar que a adoção dessas ações, além de garantir condições de desenvolvimento econômico e boa qualidade de vida para as próximas gerações, ainda incita a adoção de novos posicionamentos no que se refere à proteção e conservação ambiental. Entretanto, há teóricos que afirmam que está muito distante a efetivação dessas ações, ou seja:

\begin{abstract}
A humanidade enfrenta problemas de degradação ambiental que remontam no tempo. O ambiente, que sempre desempenhou sua função depuradora com eficiência, encontra-se hoje excessivamente sobrecarregado pelas atividades antrópicas: sofre o risco de exaustão dos seus recursos, não conseguindo em determinadas situações, recuperar-se por si só, necessitando o auxílio do homem. Porém, considerando os atuais modelos de produção e desenvolvimento que priorizam a maximização econômica em detrimento à conservação ambiental, a solução definitiva dessas questões parece estar distante de ser encontrada [...] (SOUZA, 2004, p. 2)
\end{abstract}

Desse modo, quando se busca estabelecer uma relação interdependente entre a sustentabilidade e a proteção do ambiente, sempre se esbarra em obstáculos de cunho político-econômico e sociais, fazendo entender que

[...] a grande dificuldade para a adoção de uma atitude consciente e precavida de buscar estabilizar o nível de consumo de recursos naturais está em que esta estabilização pressupõe uma mudança de atitude que contraria a lógica do 


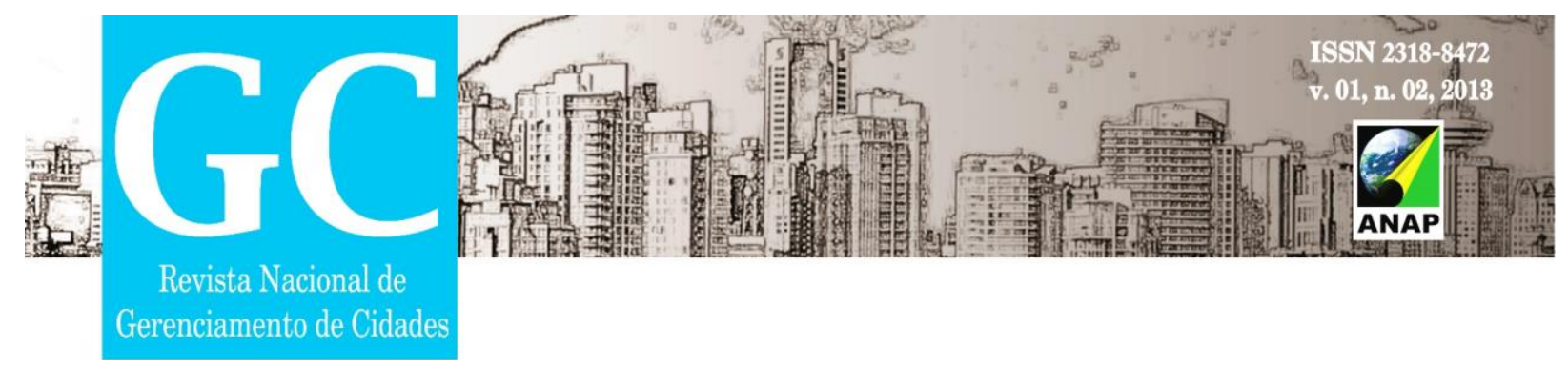

processo de acumulação de capital em vigor desde a ascensão do capitalismo. (ROMEIRO, 1999, p. 6)

Para o autor, o que caracteriza a ascensão das sociedades capitalistas modernas é a abolição de restrições de caráter religioso, estético, cultural e social, às quais a racionalidade econômica estava subordinada. Com isso, o capitalismo consegue fazer com que $o$ uso dos recursos humanos e naturais passa a ter quase nenhum controle social, o que demanda a criação de novos valores socioculturais.

Entretanto, é preciso sublinhar que existe, também, um conjunto de fatores - não estritamente ecológicos que podem ter um papel coadjuvante importante numa mudança desses valores que sinaliza a adoção de padrões de consumo mais equilibrados ecologicamente. Entre estes fatores vale ressaltar três: "os riscos ligados à qualidade de produtos essenciais (como os alimentos), a própria ideia de que o aumento da afluência material implica sempre no aumento do bem estar e a difusão da tese de que o sistema capitalista é eficiente, mas não produz justiça social". (ROMEIRO, 1999, p.7)

O grande obstáculo à implementação da sustentabilidade está no fato de que as autoridades não só não acabaram como continuam a criar e administrar leis, políticas, taxas e subsídios que tornam as medidas e/ou ações em favor dessa implementação, antieconômicas. O autor mostra esse obstáculo na prática quando enfatiza com veemência que:

No caso dos serviços ambientais não transacionados no mercado devido sua natureza de bens públicos, o mecanismo de ajuste proposto não leva em conta princípios ecológicos fundamentais para garantir a sustentabilidade, na medida em que este mecanismo é baseado no cálculo de custo e benefício feito pelos agentes econômicos visando à alocação de recursos entre investimentos em controle da poluição e pagamentos de taxas por poluir de modo a minimizar o custo total. $\mathrm{O}$ cálculo das taxas, por sua vez, será baseado num conjunto de metodologias de valoração econômica que mensuram direta ou indiretamente a disposição a pagar dos indivíduos por bens e serviços ambientais. Portanto, o ponto de equilíbrio, chamado de poluição ótima, é de equilíbrio econômico e não ecológico, pois ecologicamente não se pode falar em equilíbrio quando a capacidade de assimilação do meio é ultrapassada, como é o caso uma vez que a poluição permanece. (ROMEIRO, 1999, p. 6) 


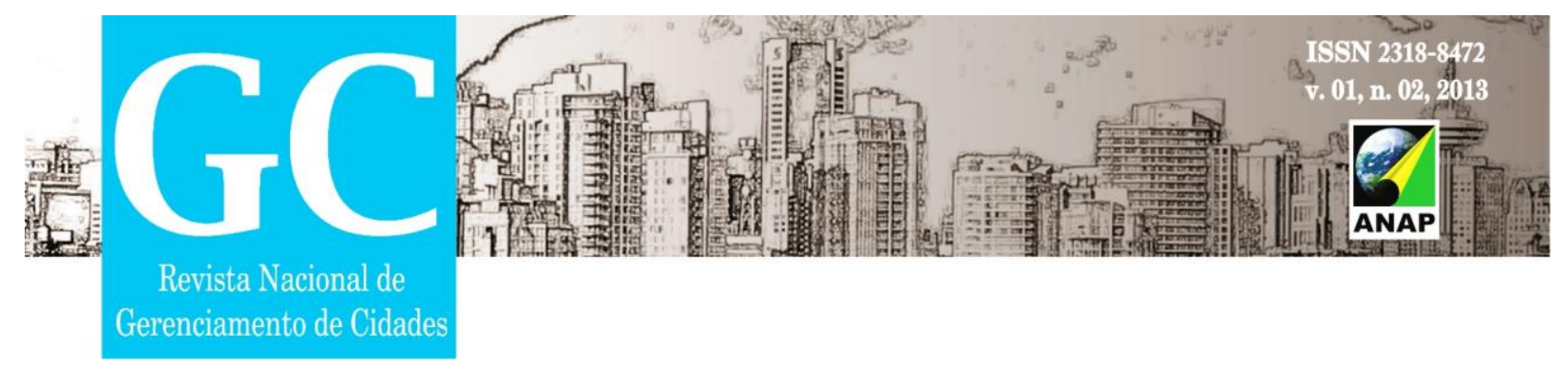

Consideradas as argumentações do autor acima citado, pode-se dizer que adotar uma consciência e desenvolver atitudes precavidas, é assumir uma postura prática de reduzir o máximo possível o desenvolvimento de ações que degradam o meio ambiente, enquanto se aceleram as pesquisas científicas destinadas a avaliar melhor os riscos envolvidos no processo de desenvolvimento econômico e encontrar alternativas de racionalização dos recursos naturais.

Embora, a definição do quanto seria este máximo possível seja controvertida, já que de um lado estão às considerações ecológicas e de outro, as considerações de ordem político/econômica e de ordem técnico-científica, o que se sabe é que "o ambiente sofrerá menos ações antrópicas quando existir solidariedade das gerações presentes, concentradas nos países afluentes, em relação às gerações futuras e às populações dos países pobres". (ROMEIRO, 1999, p. 8)

Conforme o raciocínio do autor, um exemplo real da relutância dos países capitalistas em relação às demandas e legislações de proteção ambiental e, mais especificamente, em relação à sustentabilidade é o posicionamento dos governos americanos em relação ao Protocolo de Kyoto que entrou em vigor em 2005 reflete em última análise o sentimento de que a opinião pública americana não aceitaria pagar o preço, nesse caso a solidariedade das gerações presentes comas gerações futuras implicaria, entre outras coisas, na redução do uso de recursos minerais. Portanto, para minimizar os obstáculos político-econômicos e sociais frente à sustentabilidade, exige certos tipos de procedimentos de natureza global.

Um desses procedimentos, para efeito de conscientização e mudança de posturas com relação à proteção/conservação do meio ambiente é contextualizar conhecimentos sobre o capitalismo, "entendendo-o como um sistema econômico, social e político que se baseia nas propriedades privadas e seus meios de produção, considerando-se que a produção, a concorrência e a distribuição da riqueza são decididas livremente pelo mercado". (LEANDRO, 2008, p. 1) 


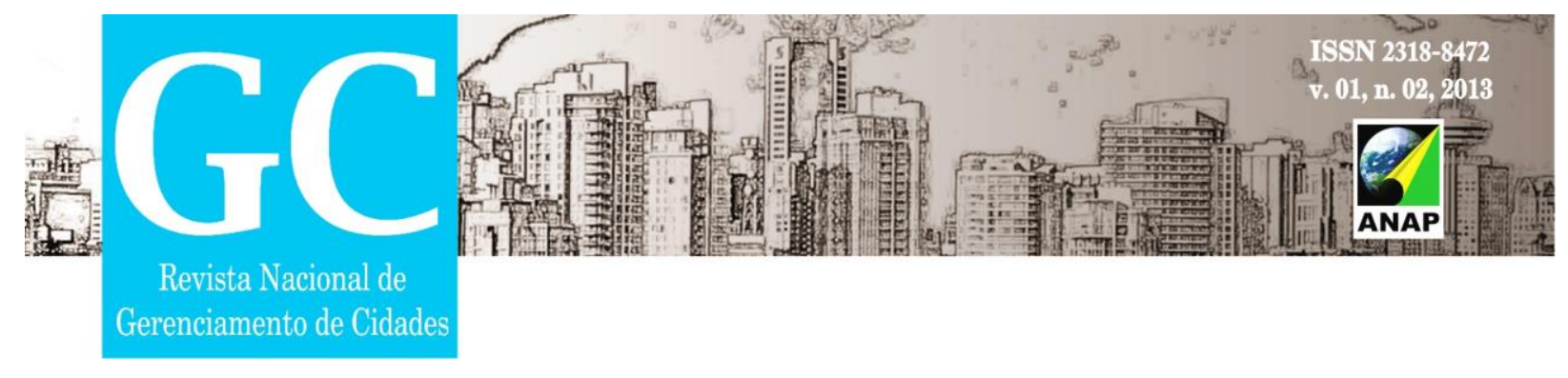

Parece faltar a compreensão uma maneira de ver a inter-relação homem/natureza. O fundamental é o trabalho de conscientização que vise a criar atitudes práticas de defesa e proteção do ambiente. Sob o ponto de vista do professor Ab'Sáber (1990, p. 16), "a Educação Ambiental é o conhecimento da estrutura, da composição e da funcionalidade da natureza, das interferências que o homem produziu sobre essa estrutura, essa composição e essa funcionalidade".

O reflexo de toda essa ação gera o efeito predatório. Produção, consumismo e degradação ambiental em detrimento do desenvolvimento e do lucro são as palavras de ordem para que esse sistema continue em expansão. Como o capitalismo é baseado na produção e no consumo, e não há mais tantos recursos naturais disponíveis para serem utilizados como matéria-prima, está acontecendo um colapso na produção, sem dinheiro e sem produtos, os capitalistas estão sendo obrigados a pensar de forma sustentável.

Emerge aqui, outro procedimento que visa minimizar os obstáculos políticoeconômicos e sociais frente à sustentabilidade: "incluir na produção e no consumo pessoas que não fazem parte do capitalismo seria o que estudiosos chama de Base da Pirâmide, oferecendo maneiras de que essa pirâmide possa gerar capital, atuando conforme sugere o tripé da sustentabilidade, com visão econômica, social e ambiental, integradas". (LEANDRO, 2008, p. 1)

Tão importante quanto conhecer, de fato, o capitalismo e a inclusão do fenômeno Base da Pirâmide, é a transformação efetiva do conceito de sustentabilidade no ativo das empresas e governos. Esse procedimento possibilitará que o sistema capitalista funcione de forma mais justa, deixando de punir a natureza e os países mais pobres.

Como todo o equilíbrio ambiental tem relações complementares, também a adoção de medidas para sustentar esse equilíbrio depende de ações complementares e/ou intervenientes. Sendo assim, outro procedimento minimizador dos obstáculos políticoeconômicos e sociais frente à sustentabilidade é proposto pela UNESCO (2005, p. 42), que é "a educação para o desenvolvimento sustentável, capaz de promover valores porque induz o estabelecimento de relações caracterizadas pela justiça, paz e negociação de 


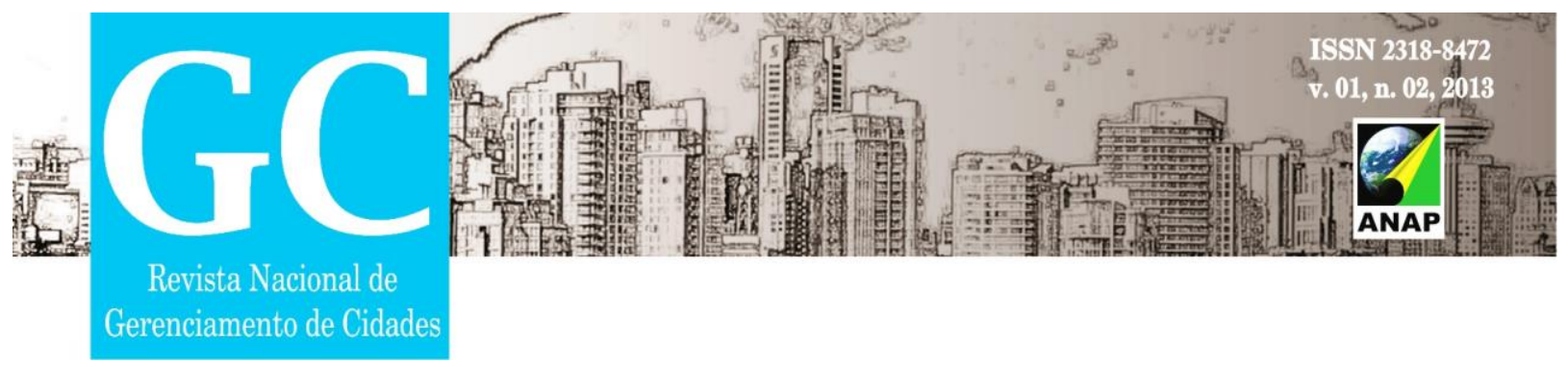

interesses mútuos geram mais igualdade, respeito e compreensão". São estas qualidades que irão fundamentar o desenvolvimento sustentável. Os papéis-chave da educação para o desenvolvimento sustentável são:

\begin{abstract}
- A educação deve inspirar a crença que cada um de nós tem o poder e a responsabilidade de introduzir mudanças positivas em escala global.

- A educação é o principal agente de transformação para o desenvolvimento sustentável, aumentando a capacidade das pessoas de transformarem sua visão de sociedade em realidade.

- A educação incentiva os valores, comportamento e estilos de vida necessários para um futuro sustentável.

- A educação para o desenvolvimento sustentável é um processo em que se aprende a tomar decisões que levem em consideração o futuro em longo prazo de igualdade, economia e ecologia de todas as comunidades.

- A educação fortalece a capacidade de reflexão orientada para o futuro. (UNESCO, 2005, p. 44)
\end{abstract}

Embora esse papéis da educação tenham grande importância para a real implementação da sustentabilidade, a UNESCO adverte:

\begin{abstract}
A busca pelo desenvolvimento sustentável é multifacetada - não pode depender unicamente da educação. Muitos outros parâmetros sociais afetam o desenvolvimento sustentável, como, por exemplo, a governança, relações de gênero, formas de organização econômica e de participação dos cidadãos. $\mathrm{Na}$ realidade, seria preferível falar em aprendizagem para o desenvolvimento sustentável, já que aprender não está restrito à educação como tal. Aprender inclui o que acontece nos sistemas educacionais, mas se estende na vida cotidiana - de modo que importantes aspectos da aprendizagem acontecem em casa, em contextos sociais, em instituições comunitárias e no local de trabalho. Embora rotulada de Década da Educação para o Desenvolvimento Sustentável, ela deve abranger e promover todas as formas de aprendizagem (UNESCO, 2005, p. 44).
\end{abstract}

Ainda, em consonância com a UNESCO (2005, p. 46), "a educação para o desenvolvimento sustentável deve compartilhar as características de qualquer experiência de aprendizagem de qualidade, com os critérios adicionais de que o processo de aprendizagem/ensino deve servir de modelo para os valores do próprio desenvolvimento sustentável". A educação para o desenvolvimento sustentável não deve ser equiparada à Educação Ambiental (EA), mesmo que desenvolvimento sustentável englobe $E A$, colocando-a no contexto mais amplo dos fatores socioculturais e questões sociopolíticas 


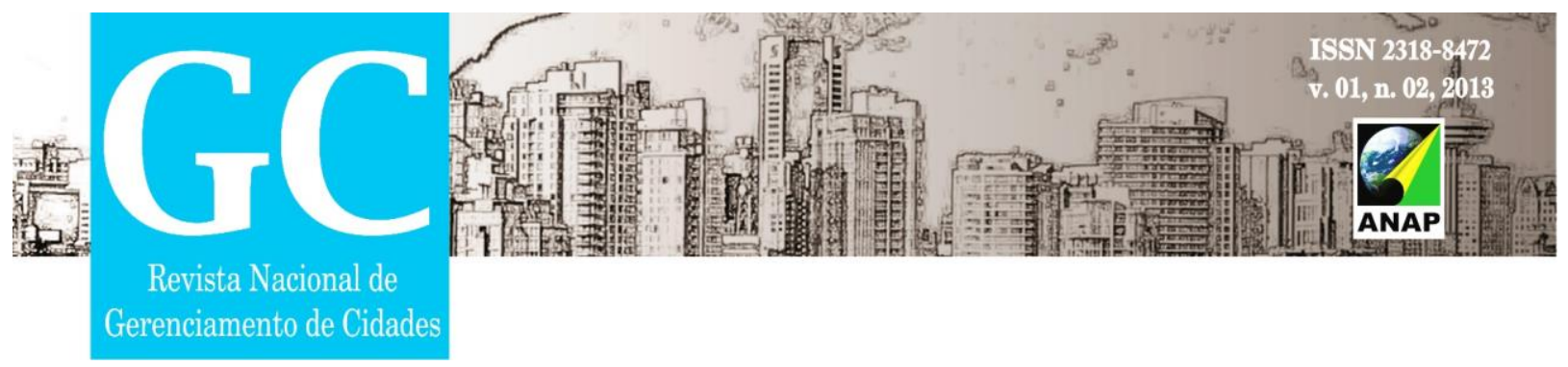

de igualdade, pobreza, democracia e qualidade de vida. Mais detalhadamente, a UNESCO esclarece que:

A educação para o desenvolvimento sustentável deveria possuir as seguintes características:

- Ser interdisciplinar e holística: aprendizado voltado para o desenvolvimento sustentável como parte integrante do currículo como um todo, não como uma matéria separada;

- Ter valores direcionados: é imprescindível que as normas assumidas os valores e princípios compartilhados a- que sirvam de base para o desenvolvimento sustentável - sejam explícitas de modo que possam ser analisadas, debatidas, testadas e aplicadas;

- Favorecer o pensamento crítico e as soluções de problemas: que gere confiança para enfrentar os dilemas e desafios em relação ao desenvolvimento sustentável;

- Recorrer a múltiplos métodos: palavra, arte, teatro, debate, experiência, pedagogias diferentes que deem forma aos processos. É preciso passar do ensino destinado unicamente a transmitir conhecimento para um enfoque em que professores e alunos trabalhem juntos para adquirir conhecimentos e transformar o espírito das instituições educacionais do entorno [...] (UNESCO, 2005, p. 47)

Em síntese, estabelecer uma relação de soma entre sustentabilidade e ambiente não depende somente de procedimentos analisados e desenvolvidos, tais como os que foram descritos. O estabelecimento dessa relação é uma possibilidade complexa, dadas os retrocessos legais e a falta de compromisso das nações, governos, empresas e sociedade com a proteção/conservação do mesmo.

Um desses retrocessos são alguns pontos polêmicos no debate ambiental, ou seja, o debate dos problemas ambientais nos diferentes meios, em especial, nos meios de comunicação, tem levado à formação de alguns preconceitos e à veiculação de algumas imagens distorcidas sobre as questões relativas ao ambiente. Mais grave do que os preconceitos são as distorções porque elas minimizam os problemas ou banalizam princípios e valores ambientais.

De acordo com Brasil (1998, p. 67), "no que se refere à prática efetiva da sustentabilidade em consonância com a proteção/conservação do ambiente, independentemente da abrangência com que se abordam as questões ambientais". É preciso visualizar a existência de alternativas ambientalmente equilibradas. Em outras palavras, é preciso que as distorções deem lugar à veiculação de procedimentos 


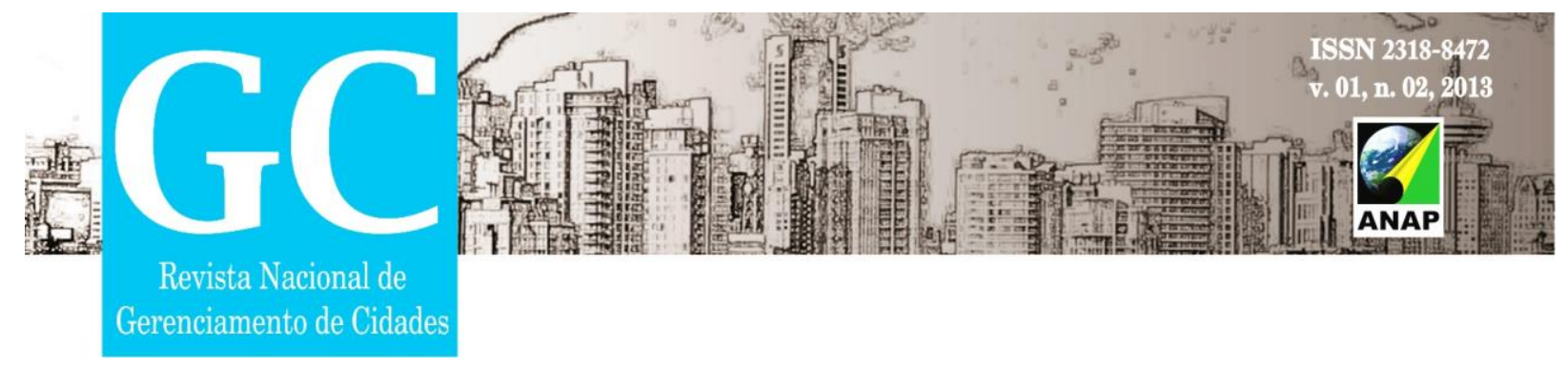

adequados e acessíveis para a humanidade desenvolver capacidades ligadas à participação, à corresponsabilidade e à solidariedade entre as gerações.

\section{CONSIDERAÇÕES}

Este estudo permitiu concluir que muitos são os conceitos de sustentabilidade e muitos são os procedimentos cabíveis para esse processo e/ou fenômeno se efetive a curto e médio prazo. Pode-se dizer que a degradação ambiental é o processo gerador de perda ou redução de características originais do ambiente e que a sustentabilidade é a utilização de toda a potencialidade de produção sem deixar de visar o bem-estar humano e do ambiente, tanto no presente quanto para as gerações futuras.

Ainda que o termo desenvolvimento econômico e/ou sustentabilidade esteja muito relacionado à questão ambiental, seu significado vai muito além, pois essa prática desenvolvimento sustentável é uma tarefa complexa que tem conexões com cada parte da vida. Ao objetivar traçar um paralelo entre sustentabilidade e degradação ambiental é fundamental para que se mantenham essas conexões, de modo que todo aprendizado possa dar possibilidades de se aplicar os princípios do desenvolvimento sustentável na vida de cada indivíduo, de forma que ele possa compreender as múltiplas repercussões de suas ações e comportamento frente à questão ambiental.

É importante reconhecer a diferença entre conhecimento científico e prática político-econômica e social, ou seja, apesar do grande volume de conhecimento existente, os interesses econômicos e a cultura de consumo vigente exercem uma maior influência sobre os efeitos admissíveis e os mecanismos regulatórios em questões ambientais.

Neste sentido, a sustentabilidade distanciada e/ou dissociada da degradação ambiental, tem sua implementação mais entravada nos países subdesenvolvidos ou em desenvolvimento por conta de uma série de mecanismos ligados a questões globais. Por força das circunstâncias capitalistas existem, nesses países, implicações ambientais 


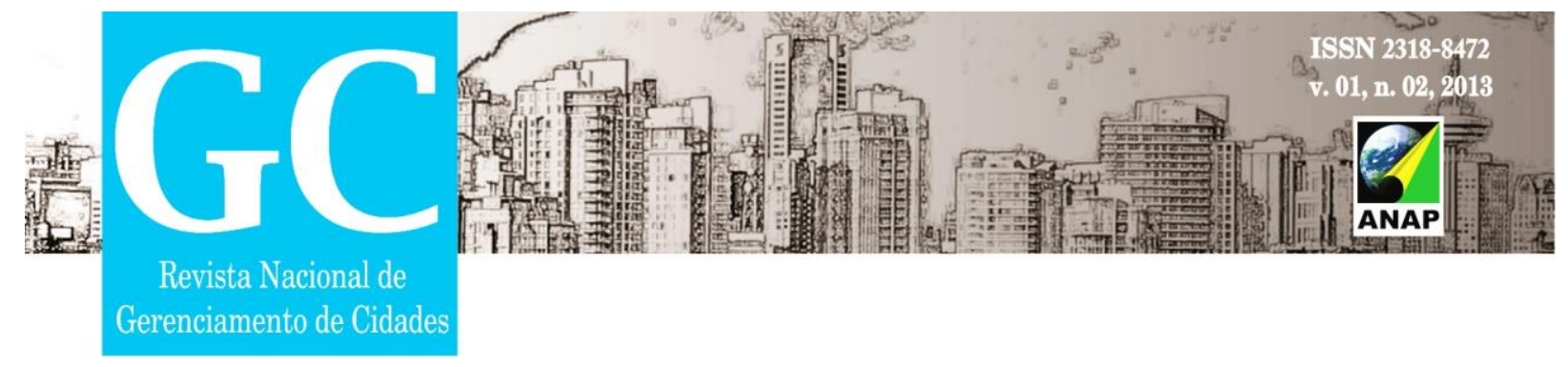

perversas, fazendo com que os efeitos das políticas e da degradação sejam mais incisivos sobre o terceiro mundo.

Mesmo que procedimentos como contextualizar conhecimentos sobre o capitalismo, incluir na produção e no consumo pessoas que não fazem parte do capitalismo e a adoção da educação para o desenvolvimento sustentável se torne efetivos, a maior alavanca para a implementação da sustentabilidade é a conscientização da necessidade de se proteger e conservar o ambiente.

Essa conscientização, de forma global e generalizada, tende a seruma das estratégias mais eficazes para barrar os processos de degradação ambiental sofridos pelo planeta, entretanto, deve-se levar em conta que essa conscientização se dá, inegavelmente, através do ensino ecológico e é capaz de gerar mudanças nos hábitos e atitudes das ações humanas para alcançar o bem-estar pleno e um ambiente, sustentável, sadio e equilibrado.

Assim, a questão ambiental impõe às sociedades buscar novas formas de pensar e agir, individual e coletivamente, de novos caminhos e modelos de produção de bens, para suprir necessidades humanas, e relações sociais que não perpetuem tantas desigualdades e exclusão social, e, ao mesmo tempo, que garantam a sustentabilidade ecológica. Isso implica um novo universo de valores no qual a Educação Ambiental tem um importante papel a desempenhar.

\section{REFERÊNCIAS}

AB'SÁBER, A. O que é Educação Ambiental? In: Revista Sala de Aula III, Abril, 1990, p.16.

ALMANAQUE ABRIL. Degradação ambiental. São Paulo. Ed. Ática, 2007, p. 53-55. 


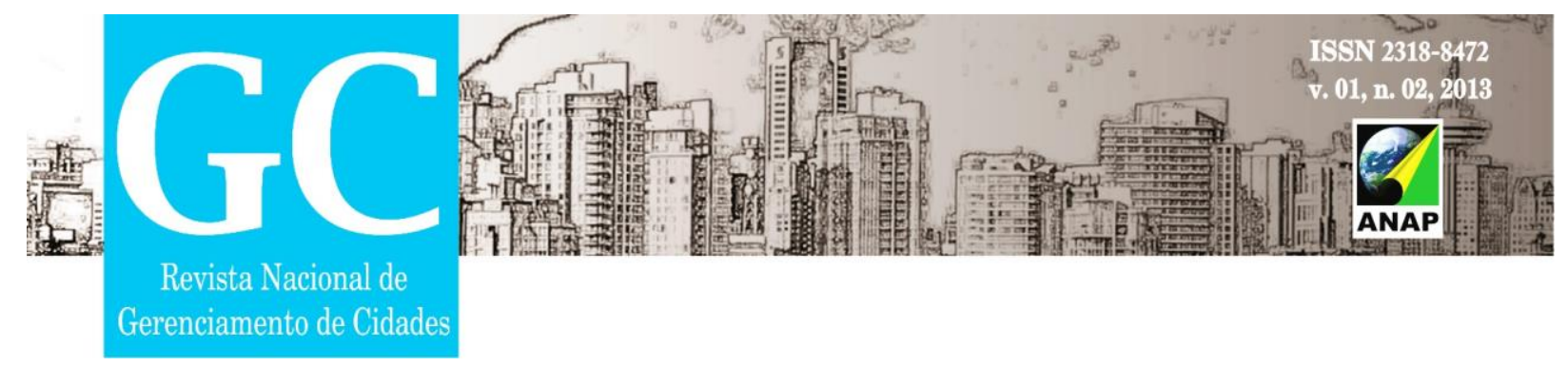

BRASIL. Secretaria de Educação Fundamental. Parâmetros Curriculares Nacionais: terceiro e quarto ciclos: apresentação dos temas transversais / Secretaria de Educação Fundamental. - Brasília: MEC/SEF, 1998, p. 67.

JACOBI, P. Educação Ambiental, cidadania e sustentabilidade. In: Cadernos de pesquisa, n. 118, 2003, p. 1.

LEANDRO, E. O. Capitalismo e sustentabilidade. Publicado em: 13/out./2008, p.1. Disponível em: http://evelynleandro.wordpress.com Acesso em 15/mai.2013.

LOUREIRO, D. G. Educação e meio ambiente. In: TOCANTINS. Fundação Universidade do Tocantins UNITINS/Empresa de Educação Continuada Ltda. EDUCON. Normal Superior. - Palmas: UNITINS / EDUCON, 2007, p. 38.

LUNA, S. V. de. Planejamento de pesquisa: uma introdução. São Paulo: PUCSP, 1997, p. 8.

REIGOTA. M. Meio ambiente e representação social. 3. Ed. São Paulo: Cortez, 1998, p. 14.

ROMEIRO, A. R. Economia ou economia política da sustentabilidade. In: ROMEIRO, A. R. Desenvolvimento sustentável e mudança institucional: notas preliminares. Econômica, Revista da UFF, V. 1, N. 1, 1999, p. 6-8.

RUSCHEINSKY, A. No conflito das interpretações: o enredo da sustentabilidade. In: Rev. Eletrônica Mestr. Educ. Ambiental - ISSN 1517-12567. Vol. 10, jan.jun./2003, p. 41.

SOUZA, M. N. Degradação e recuperação ambiental e desenvolvimento sustentável. URI: http://hdl.handle.net/123456789/2441. Data: 2004, p. 2. Disponível em: http://www. bibliotecaflorestal. ufv.br. Acesso em 15/mai./2013.

UNESCO: Década da Educação das Nações Unidas para um desenvolvimento sustentável, 2005-2014: documento final do esquema internacional de implementação. Brasília: UNESCO, 2005, p. 45-47.

Site visitado: http://www.portaldaeducação.com.br/biologia/artigos. Acesso em 15/mai./2013. 


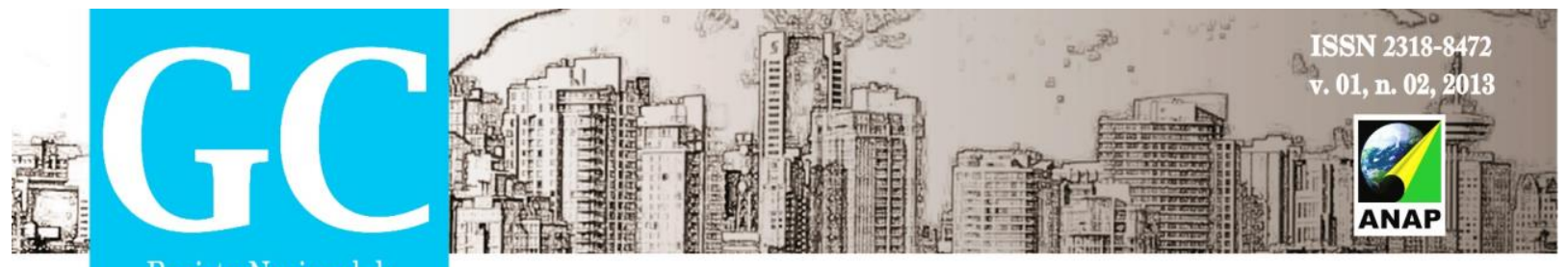

Revista Nacional de

Gerenciamento de Cidades 